South African Journal of Geomatics, Vol. 3, No. 2, August 2014

\title{
Quantifying Savanna Woody Cover in the Field and on Historical Imagery: A Methodological Analysis
}

\author{
Ndidzulafhi Innocent Sinthumule ${ }^{1}$, Chris Munyati $^{2}$ \\ ${ }^{1}$ Department of Ecology and Resource Management, University of Venda, Thohoyandou, \\ South Africa, Innocent.Sinthumule@ univen.ac.za \\ ${ }^{2}$ Department of Geography and Environmental Science, North West University (Mafikeng \\ Campus), Mmabatho, South Africa
}

DOI: http://dx.doi.org/10.4314/sajg.v3i2.1

\begin{abstract}
The proliferation of woody vegetation on open grass savannas constitutes degradation in rangeland quality. Historical high spatial resolution satellite imagery in archive provides possibilities for assessing increase in woody vegetation cover on the rangelands. This paper examines the quantification of woody vegetation in the field and on historical high spatial resolution imagery, using the southern granites research supersite in the Kruger National Park (KNP) as test case. The recently established research supersites represent the key characteristics of the vegetation zones in the KNP. Field quantification of woody cover was undertaken in June and September 2013 by employing a detailed procedure that quantified the area covered by individual woody (tree, shrub) canopies at twelve one hectare sample plots. The area covered by the woody individuals at the respective plots was then totalled in order to yield the fraction (\%) of cover per hectare. The woody cover data were then related to test recent historical imagery in order to assess woody cover estimation procedures on historical imagery. Digital high spatial resolution aerial photographs (dated 2010) and dry period (spring/autumn) SPOT multispectral images (September 2001, April 2012) were used; the dry period dates selected so as to eliminate herbaceous vegetation from the analysis. For the newest (2012) image, sub-pixel classification correctly assigned woody cover at the field sample plots to their 2013 field-derived cover fractions. The results indicate that sub-pixel classification, validated by detailed field quantification of woody cover, can accurately map woody encroachment on savanna rangelands using historical high spatial resolution imagery.
\end{abstract}

\section{Introduction}

Savanna rangelands in Africa provide habitat for a variety of ungulates (du Toit \& Cummings, 1999), which makes their conservation of biodiversity significance. Deterioration in their quality results in reduced carrying capacity for these ungulates, as well as associated negative effects on biodiversity. There is, therefore, an acute need for spatial data on the condition of savanna rangelands. 
One of the mechanisms by which savanna rangeland quality deteriorates is the proliferation of woody vegetation at the expense open grass grazing land, known as bush encroachment. Bush encroachment on savannas manifests through conversion of the savannas to dense, acacia-dominated thickets with little grass cover (Meik et al., 2002). The encroaching species are often unpalatable to grazers (Kraaij \& Ward, 2006) or not accessible to browsers if thorny (Moleele et al., 2002). The availability of high spatial resolution digital satellite imagery, as well as improved image processing algorithms that enable discrimination of woody vegetation, permits the monitoring of bush encroachment. However, difficulties in quantifying the woody cover both in the field and on historical imagery limit the full utilisation of this capability. Part of the problem lies in the characteristically scattered and patchy nature of savanna woody cover. The scattered nature of the cover presents spatial quantification difficulties both in the field using quantification instruments, and in mapping the cover using image classification algorithms. In the field, the woody cover is sometimes quantified by visual estimation (e.g. Oldeland et al., 2010; Shackelton, 2000), which can be subjective.

Since high spatial resolution imagery only dates back to the mid 1980s, historical aerial photographs enable an extension of high spatial resolution analysis of bush encroachment to periods before then. Appropriate digital image processing protocols and algorithms are needed to enable this linkage between multispectral satellite imagery and historical aerial photographs, most of which are panchromatic. The common approaches to mapping woody cover on such imagery in bush encroachment studies are the use of traditional pixel-based image classification (e.g. Hudak \& Wessman, 1998; 2001) and object-oriented classification (e.g. Laliberte et al., 2004; McGlynn \& Okin, 2006), although some studies have used manual quantification on aerial photographs (e.g. O'Conner \& Crow, 1999). Hudak and Wessman (1998) utilised pixel-based image classification of the severity of encroachment based on photo texture on a $2 \mathrm{~m}$ spatial resolution set of historical aerial photographs that were later spatially related to lower spatial resolution $(\leq 10 \mathrm{~m})$ satellite imagery by pixel aggregation. LaLiberte et al. (2004) utilised image segmentation to discriminate shrub encroachment on an imagery dataset that included very high spatial resolution $(0.60 \mathrm{~m})$ QuickBird multispectral imagery that was at nearly the same spatial resolution as the panchromatic historical aerial photographs.

Pixel-based approaches to quantifying bush encroachment suffer from the error of overestimation in that whole pixels can be assigned to woody cover when the woody cover is only dominant and not covering the entire pixels concerned. Proponents of the use of objectoriented classification in mapping bush encroachment stress the advantage that it groups adjacent pixels into contiguous multi-dimensionally homogenous clusters that represent natural land cover patterns and minimize classification errors that result from single pixels with outlier values and areas of complex spectra due to mixed coverage (Laliberte et al., 
2004; McGlynn \& Okin, 2006). However, such approaches appear inappropriate for mapping and quantifying the actual woody cover on savannas in that aggregating woody cover that is inherently patchy in nature amounts to introducing over-estimation error. Sub-pixel classifiers such as spectral mixture analysis (SMA) offer a more accurate alternative. Spectral mixture analysis calculates the fraction of cover (as a decimal) by land cover classes of interest per pixel. Locations that represent pure coverage by the cover classes of interest (i.e. 'end members') are identified and specified during SMA (Pan \& Li, 2013). The technique potentially can have high land cover classification accuracy on digital images.

In this paper we demonstrate methods for quantifying woody vegetation cover in the field and on historical imagery. We use a section of the Kruger National Park in South Africa as test case. Historical high spatial resolution aerial photographs and SPOT imagery were used. In particular, we examine sub-pixel classification in the quantification of woody vegetation cover by testing it against detailed field validation data. We then assess the potential of subpixel classification in monitoring bush encroachment using high spatial resolution historical aerial photographs and multispectral imagery.

\section{Materials and Methods}

\subsection{Study sites}

Savanna vegetation in the Kruger National Park (KNP; Figure 1a) was utilised for the study. The geology of the KNP broadly consists of high fertility basalts in the eastern half, and low fertility granites in the west (Figures 1b,c). The structure of the Park's vegetation is influenced by the geology, with the basalts predominated by more open short tree cover and sweet grass, and tall tree woodland with a sweet and sour grass mixture on the granite substrates (Gertenbach, 1983). The sweet grass in the Park's basalt substrate zone is heavily grazed (van Wilgen et al., 2000). Structurely, the woody vegetation ranges from shrubs of $<1 \mathrm{~m}$ height to tall trees $>10 \mathrm{~m}$, with a variety of species of many genera like Acacia, Combretum, Grewia, Terminalia, etc (Gertenbach, 1983). There is no targeted management for bush encroachment in the KNP, compared to the neighbouring private protected areas.

Management in the KNP recently established four research supersites that encompass the Park's geology and rainfall characteristics (Smit et al., 2013). We utilised two of the research supersites for this study (Figure 1c), the one in the southwest (Site A - the Southern Granites supersite) and the one in the south-eastern sector (Site B - the Southern Basalts supersite).

\subsection{Field quantification of woody vegetation cover}

The first stage of the work was to obtain sample quantitative data on woody vegetation cover in the field at the two study sites. As opposed to visual estimation, we sought actual detailed measurements. We judged densiometer crown cover measurements to be unsuitable due to the scattered tree nature of woody cover on the savannas in the study area (Figure 2). 
A densiometer reading was only indicative of crown cover by individual tall trees and difficult to use in the case of short shrubs.
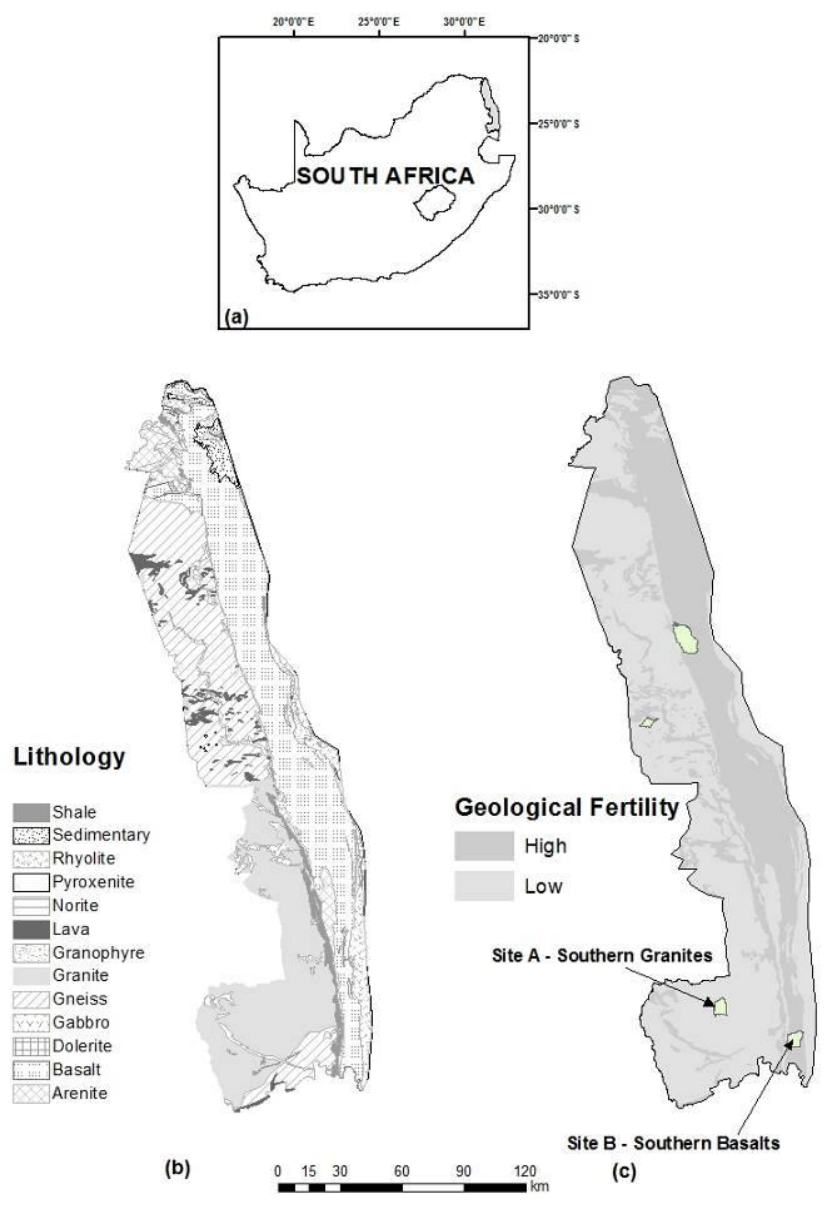

Figure 1. Location of the Kruger National Park study area in South Africa (a), the Park's geology (b) and study sites in relation to geological fertility (c). Geology data from the 1:1M geology map of South Africa (Council for Geosciences, Pretoria, South Africa).

We, therefore, devised a methodology to determine the total area of cover by individual woody canopies per unit area. We decided to use a hectare as the unit area, and measured the canopy diameter $(d)$ of each woody individual within a $100 \mathrm{~m}$ x $100 \mathrm{~m}$ (1ha) plot by spreading measuring tape either beneath or above the canopy as appropriate. The canopy diameter then gave a canopy radius $(r)$ measurement $(r=1 / 2 d)$. Treating the shape covered by the canopy as circular, we then calculated the area covered by each canopy as: Area $=\pi r^{2}$. The total area covered by all woody canopies (trees, shrubs) within the 1 ha plot then gave a $\%$ woody cover value, as a fraction of the one hectare area. Geographic location of the corners and centre of the plot was then recorded, in UTM coordinates. The location of the sample sites (plots) was purposefully varied in order to yield differences in woody cover as influenced by landscape at 
each of the two sites (Site A, Site B; Figure 1c). Therefore, the woody cover measurements were replicated using the three landscape topographic positions of valley, mid-slope, and crest. The work was undertaken in June 2013 and September 2013. Six plots were eventually utilised at each of the two study sites, the numbers limited by the time-consuming nature of the work.

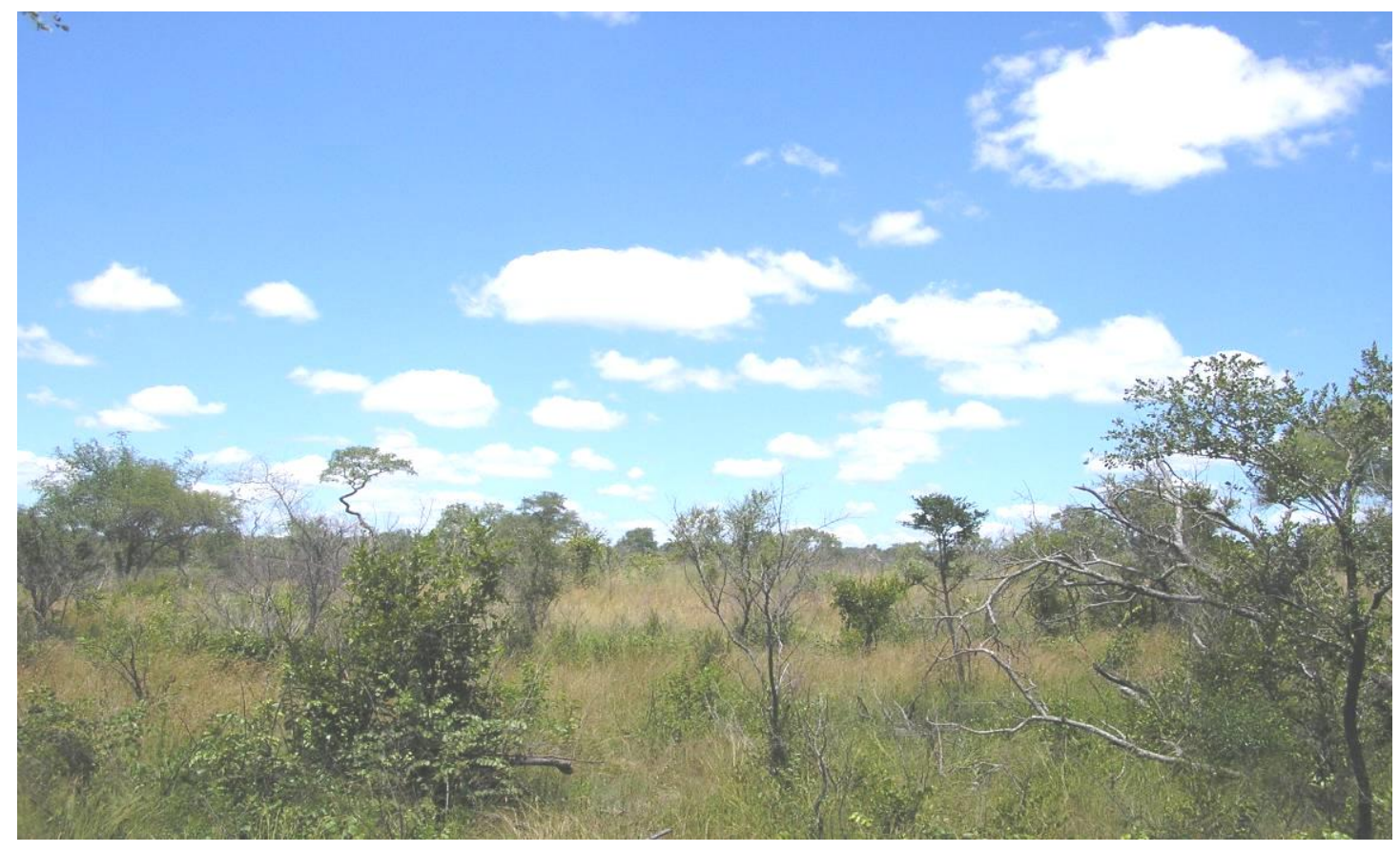

Figure 2. Illustration of the scattered nature of woody vegetation cover (trees, shrubs) on the southern granites in the Kruger National Park (photo by authors, taken at UTM coordinates [36 J 0333109, 7236281] facing north east, in March 2010).

\subsection{Image data}

Three image dates were utilised for mapping of woody cover on digital imagery. They included high spatial resolution colour aerial photographs and Systemé Pour l'Observation de la Terre 4 (SPOT 4) High Resolution Visible and Infrared (HRVIR) multispectral images (Table 1). Although the field quantification utilised both study sites (Site A, Site B; Figure 1c), we used only the more wooded Southern Granites study site for the image analysis. The images were selected mainly on the basis of availability. However, in order to differentiate the spectral signature of woody vegetation from herbaceous vegetation, season was taken into consideration when selecting the images from the list of available images. Dry season image dates were preferred in order to eliminate herbaceous vegetation from the analysis. The phenology of the herbaceous vegetation responds to rainfall events. During the rainy season (about November to March) the herbaceous vegetation is green (e.g., see Figure 2), as is the woody vegetation, but during the dry season (about April to October) herbaceous vegetation is dry. The Southern Hemisphere winter months (about June-August) were avoided because 
the trees are largely leafless in winter, which can hinder the detection of tree cover. Therefore, autumn (April) and spring (September) images were judged ideal for detecting woody cover on images, because the woody vegetation is in leaf and herbaceous vegetation dry.

Table 1 Image data covering the Southern Granites site (Figure 1c) that were tested in the mapping of woody cover

\begin{tabular}{llllr}
\hline Sensor / category & Reference & $\begin{array}{l}\text { Spectral } \\
\text { characteristic }\end{array}$ & Date & $\begin{array}{c}\text { Spatial } \\
\text { resolution }\end{array}$ \\
\hline SPOT 4 HRVIR & K/J 139/400 & Multispectral & 10 September 2001 & $20 \mathrm{~m}$ \\
Aerial photographs & - & Colour & 2010 & $0.5 \mathrm{~m}$ \\
SPOT 4 HRVIR & K/J 139/400 & Multispectral & 05 April 2012 & $20 \mathrm{~m}$ \\
\hline
\end{tabular}

The SPOT images were obtained in digital form, from the South African National Space Agency (SANSA). The aerial photographs were sourced from the National Geospatial Information (NGI) directorate in Cape Town, South Africa, in digital (scanned) format. The exact date of acquisition of these aerial photographs in 2010 was not available.

\section{$2.4 \quad$ Image processing}

\subsubsection{Pre-processing}

All the images were geometrically registered in a common projection (UTM zone $36 \mathrm{~S}$; WGS 84 datum) using image to image registration procedures. The resulting spatial registration error was sub-pixel (i.e. total RMSE $<0.50 \mathrm{~m}$ on the aerial photographs, $<20 \mathrm{~m}$ on the SPOT images). The Southern Granites site (Figure 1c) was then sub-set from the respective image scenes.

\subsubsection{Sub-pixel classification}

ERDAS Imagine 2010 was utilised for sub-pixel classification. Sub-pixel classification is implemented in a five step process in ERDAS Imagine 2010, involving pre-processing, environmental correction, signature derivation and refinement, and Material of Interest (MOI) classification (ERDAS Inc., 2010). The pre-processing, which must be performed before initiating the software's associated other sub-pixel classification processes, surveys the image for backgrounds that will be removed during signature derivation and MOI classification (ERDAS Inc., 2010). Each of the image sub-scenes resulting from the sub-setting process was, therefore, submitted to the software's pre-processing routine. Bands 1 (green), 2 (red) and 3 (near infrared) of the SPOT images were used in the analysis.

Environmental correction compensates for unwanted spectral variations in scene pixels caused by differences in atmospheric and other environmental conditions (ERDAS Inc., 
2010). The process automatically calculates environmental correction factors and outputs them to a file. These correction factors are applied within the signature derivation and MOI classification processes (ERDAS Inc., 2010). In-scene correction, which applies when the signature is used in the same scene as that from which it was derived, was selected as opposed to the scene-to-scene option. On the 2012 image that had a small amount of cloud cover (Figure 3a), sample pixels representing cloud cover were specified at this stage.

During field work sites that represented pure (mature) tree cover stands were identified and their GPS coordinates recorded. These sites were different from the sampling plots that were utilised in quantifying woody cover. For these pure tree stands spectral signature polygons were manually drawn on-screen and saved for use in the signature derivation stage, as woody cover end-members. In reality in the savanna woodlands of KNP, there are few stands with $100 \%$ tree crown cover. The average tree crown cover from the field sites was about $92 \%$, so 0.92 was specified to the software as the mean material pixel fraction (at $95 \%$ confidence level).

The last step of the sub-pixel classification process in ERDAS Imagine 2010 software is the MOI classification, using the signatures derived in the third stage of the process. Woody vegetation cover was the material of interest in this case. The MOI classification process produces a classification image that identifies detections of the material of interest and indicates the average fraction of a pixel's spatial area occupied by the material (ERDAS Inc., 2010).

For each image sub-scene, eight output classes in woody cover fraction increments of $10 \%$ were specified (i.e. $0.20-0.29,0.30-0.39$, etc). This resulted in eight classes, the maximum that the software allowed and, therefore, woody cover of less than $20 \%$ was grouped in the $<0.20$ class. The area covered by each cover fraction was then computed. The respective cover fraction spatial layers that resulted were then aggregated to the $100 \mathrm{~m}$ pixel size to facilitate comparison with the $100 \mathrm{~m} \times 100 \mathrm{~m}$ plot field data. The aggregation resulted in four woody cover fractions: $0.20-0.39,0.40-0.59,0.60-0.79$, and $0.80-1.00$. As the 2012 image was very close to the field work dates in 2013, the 2012 classification was compared with the data from the 2013 field work.

\section{Results}

Field data confirmed that granites generally have more dense woodland than the basalt substrate in KNP, with generally higher woody cover values per hectare (Table 2). For the current small number of study sites this difference was, however, not statistically significant $(t=1.575, P=0.077)$.

Figures 3-5 show the results of the sub-pixel classification of the images. Overall, the total area under woody canopies for cover fractions of at least $20 \%$ was highest (330.6ha) on the 5 April 2012 SPOT image, followed by the 10 September 2001 SPOT image (140.8ha), and 
least (97.1ha) on the 2010 colour aerial photographs (Table 3). In general on all three historical images, the sub-pixel classification generally detected high woody cover for the lower woody cover fractions $(<40 \%)$, which was in agreement with the field data in Table 2 that show the highest woody cover to have been about $40 \%$. Sub-pixel classification also detected a general pattern of high woody cover in the valleys (Figures 3-5), which also was in agreement with the pattern from the field data as shown in Table 2.

Table 2 Indicative woody canopy cover data illustrating the relationship between field data and sub-pixel classification of the images listed in Table 1

\begin{tabular}{lllll}
\hline $\begin{array}{l}\text { Study site } \\
\text { (as on }\end{array}$ & $\begin{array}{l}\text { Sample site } \\
\text { Figure 1c) }\end{array}$ & $\begin{array}{l}\text { Landscape } \\
\text { as on Figures } \\
\text { topographic } \\
\text { position }\end{array}$ & $\begin{array}{l}\text { Field } \\
\text { derived } \\
\text { woody cover } \\
\text { \% (per } \\
\text { hectare) }\end{array}$ & $\begin{array}{l}\text { 2012 image } \\
\text { classification } \\
\text { of fraction of } \\
\text { woody cover } \\
\text { (100m pixel) }\end{array}$ \\
\hline Southern granites & 1 & Valley & 40.7 & $0.20-0.39$ \\
Southern granites & 2 & Crest & 13.9 & $<0.20$ \\
Southern granites & 3 & Mid-slope & 9.2 & $<0.20$ \\
Southern granites & 4 & Valley & 8.6 & $<0.20$ \\
Southern granites & 5 & Mid-slope & 15.1 & $0.20-0.39$ \\
Southern granites & 6 & Crest & 10.7 & $<0.20$ \\
& & & & \\
Southern basalts & 1 & Crest & 13.3 & \\
Southern basalts & 2 & Crest & 4.0 & \\
Southern basalts & 3 & Mid-slope & 2.4 & \\
Southern basalts & 4 & Mid-slope & 0.5 & \\
Southern basalts & 5 & Valley & 7.7 & \\
Southern basalts & 6 & Valley & 17.0 & \\
\hline
\end{tabular}

Table 3 Area of woody cover per woody cover fraction as detected by sub-pixel classification of the Southern Granites site (Figures 3-5)

\begin{tabular}{lrrr}
\hline Woody cover fraction & \multicolumn{3}{c}{ Area (ha) } \\
\cline { 2 - 4 } & 5 April 2012 image & 2010 aerial photographs & 10 September 2001 image \\
\hline$<0.20$ & 3669.7 & 3903.2 & 3859.5 \\
$0.20-0.29$ & 50.7 & 51.6 & 43.5 \\
$0.30-0.39$ & 70.0 & 35.8 & 47.1 \\
$0.40-0.49$ & 76.1 & 5.2 & 30.2 \\
$0.50-0.59$ & 62.7 & 2.8 & 13.3 \\
$0.60-0.69$ & 40.8 & 0.8 & 5.0 \\
$0.70-0.79$ & 19.6 & 0.5 & 1.3 \\
$0.80-0.89$ & 9.0 & 0.2 & 0.3 \\
$0.90-1.00$ & 1.7 & 0.2 & 0.1 \\
Sum for fractions $\geq 0.20$ & 330.6 & 97.1 & 140.8 \\
\hline
\end{tabular}

The sub-pixel classification correctly assigned the woody cover at most of the field sample plots to their correct fraction of cover classes (Table 2). Using a contingency table, which is a simple cross-tabulation of the mapped class against that observed in the field (Foody, 2002), the overall classification accuracy was $83.3 \%$. In the absence of historical near-concurrent 
field data with which to compare it the assignment of pixels to woody cover fractions on the older imagery can, therefore, be judged to have been reliable too.

The results indicate potential for use of sub-pixel image classification in the analysis of bush encroachment on historical images through the mapping of woody vegetation cover. A sub-pixel classification procedure similar to the one employed in this study can be employed on the historical images (including panchromatic aerial photographs), provided woody cover end-member pixels are identified. Such end-member pixels can be identified on the image itself even when identification was not possible at the time the image was acquired.

\section{Discussion and Conclusion}

We recommend the woody cover field quantification and sub-pixel woody cover image classification methods utilised in this study for similar studies of savannas. The field method we describe here would avoid the rather subjective visual estimation from an oblique perspective that is sometimes resorted to, which comes with its likely errors due to subjective judgements. The method has the disadvantage of being time consuming and physically demanding and is, therefore, only suitable when there are no time constraints.

There is an element of over-estimating the woody canopy cover when assuming the canopy is circular because some canopies are oval or irregular (see Figure 2). Another source of overestimation is the fact that some canopies have inter-branch gaps. These sources of inaccuracy should be borne in mind when choosing to use the woody cover field quantification method in this study. Witkowski \& Garner (2000) used an alternative approach by calculating canopy area as: Canopy area $=\pi^{*}\left(d_{1} / 2\right) *\left(d_{2} / 2\right)$; where $d_{1}=$ longest canopy diameter, $d_{2}=$ canopy diameter perpendicular to the longest. This approach perhaps accounts for the non-circular dimensions of different tree and shrub species canopies, although identifying the longest canopy diameter appears to be an additional practical difficulty.

The spectral signatures of all woody canopies within an image scene may not be the same as the specified end-members, which can be a source of sub-pixel classification error. A possible solution for purposes of improving classification accuracy is the use of multiple endmembers in order to improve representation (e.g. Bateson et al., 2000; Dennison \& Roberts, 2003). For the savanna vegetation in this study, a number of factors can cause variation in spectral signature, including phenology, shadow, physiological stress, and herbivory. The detection required the woody canopies to be in leaf, so the absence of leaves from the woody canopy, for example due to seasonal cycles or fire damage, can result in mis-classification of woody cover. On the colour aerial photographs that were used in this study, tree shadow was a significant source of error in that, even on the same tree, sections of trees that were not on the sun-facing side were not detected as part of the woody canopy during sub-pixel classification. Physiological stress, for example moisture stress due to topographic position, can also cause differences in reflectance even within the same woody species. In the case of 


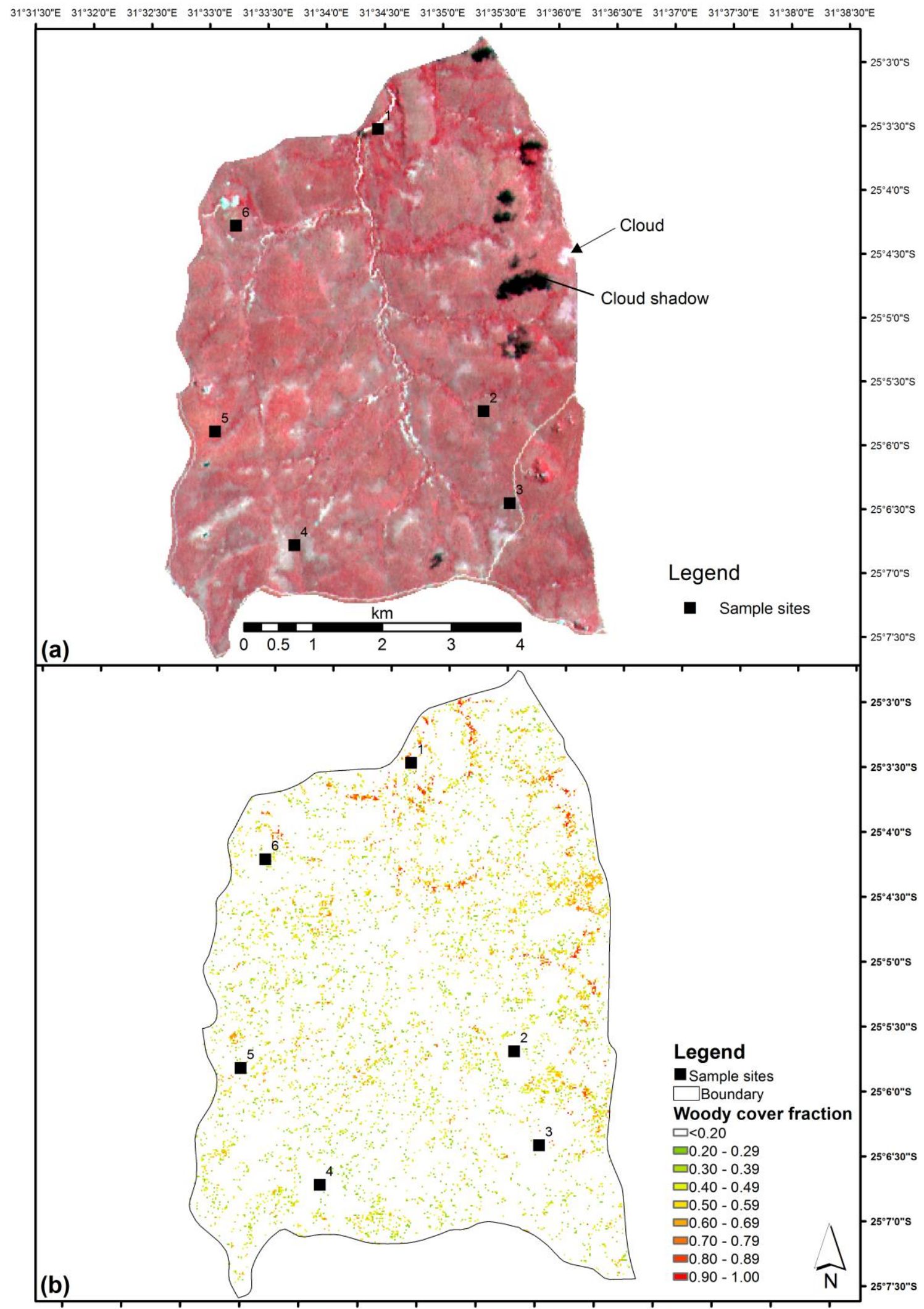

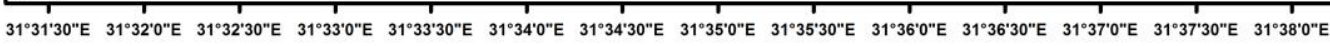

Figure 3. (a) The 5 April 2012 SPOT image (RGB:321), and (b) sub-pixel classification of woody vegetation cover on the image. 


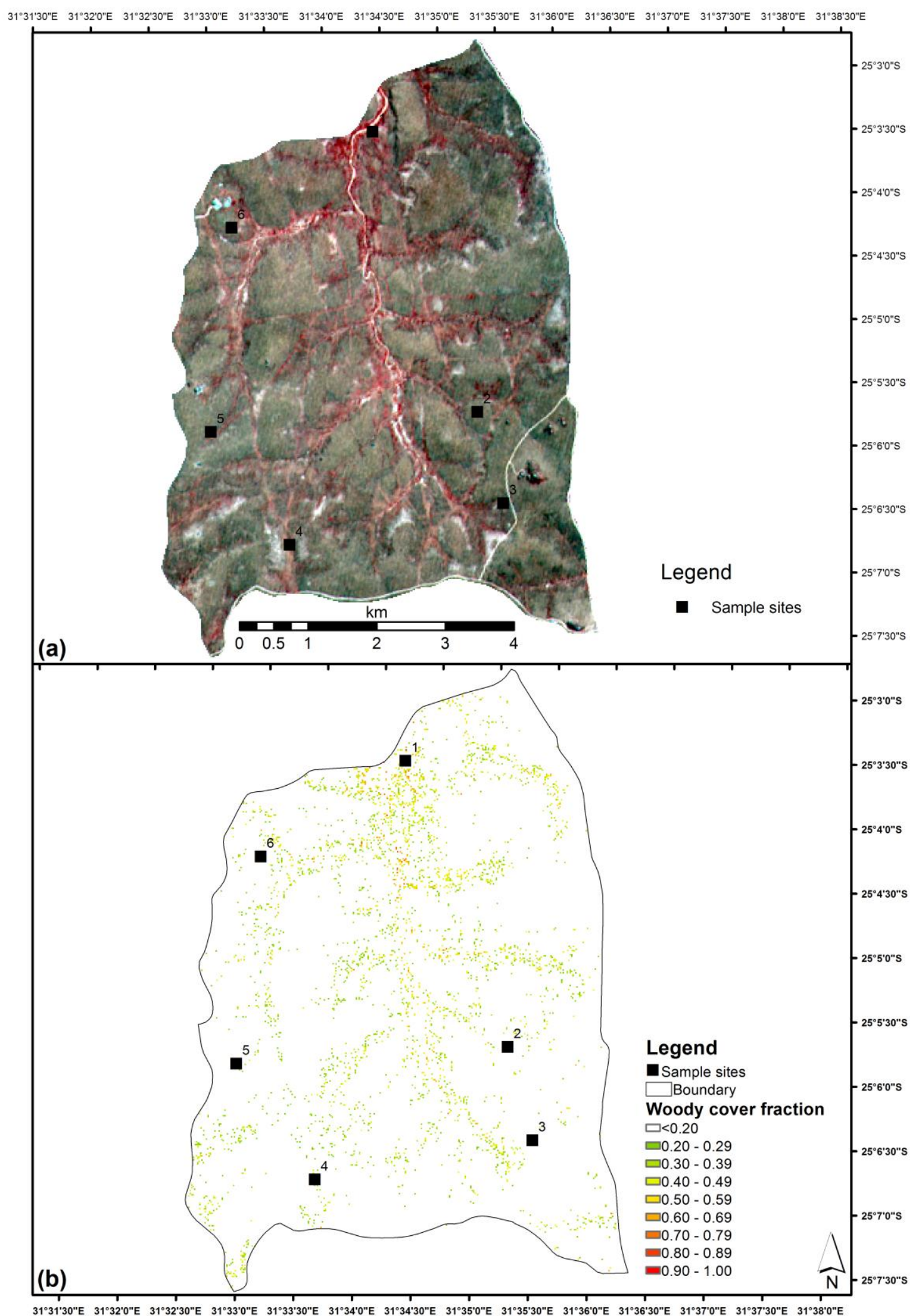

Figure 4. (a) The 10 September 2001 SPOT image (RGB:321), and (b) sub-pixel classification of woody vegetation cover on the image. 


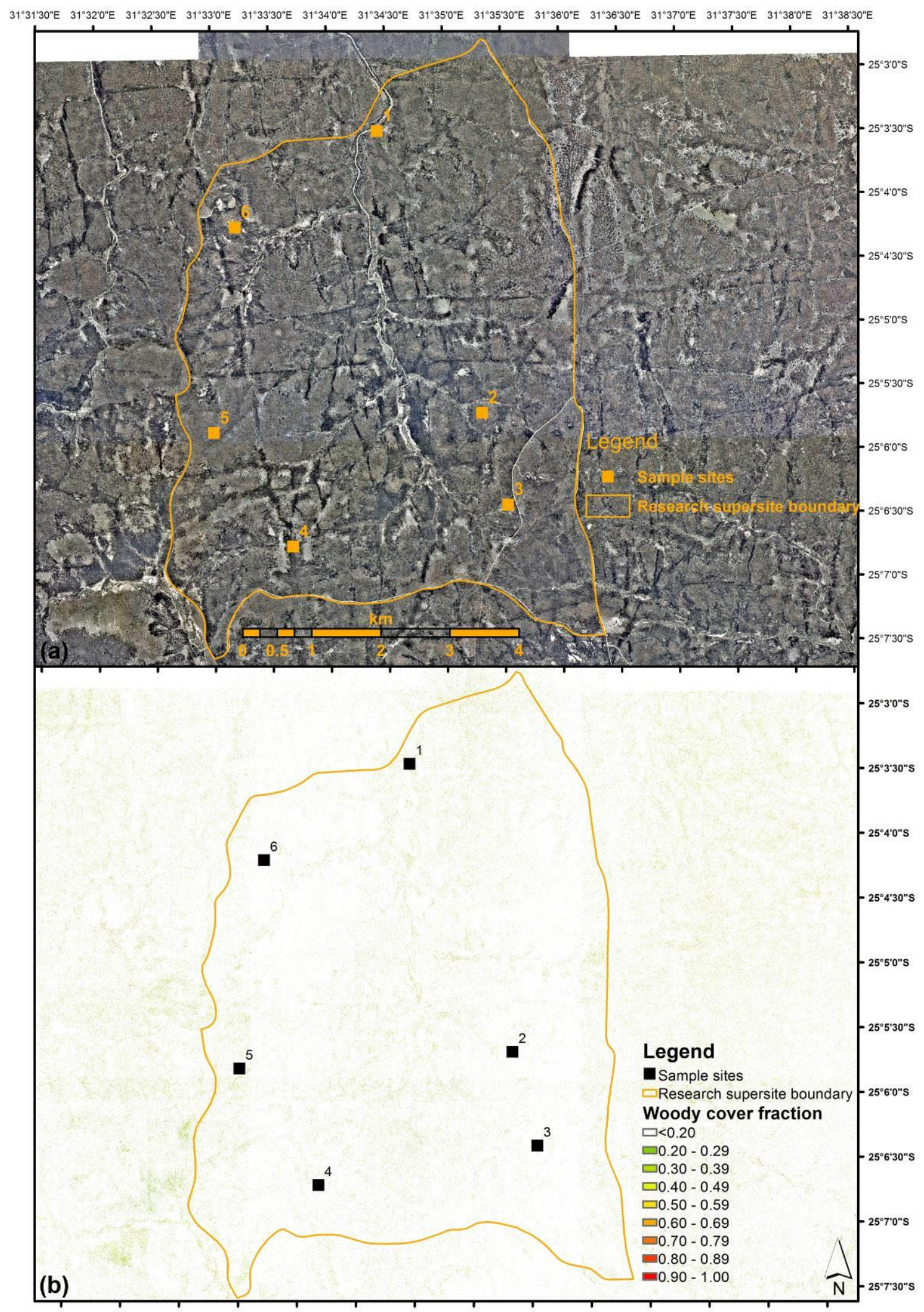

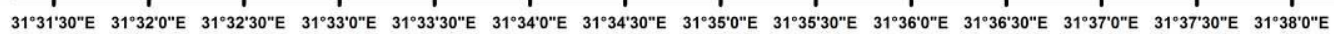

Figure 5. (a) The 2010 colour aerial photographs, and (b) sub-pixel classification of woody vegetation cover on the photographs. 
woody species that are under pressure due to browsers, herbivory can be a further source of within-species non-uniformity in spectral reflectance. Elephants can cause severe damage to woody vegetation in the Kruger National Park (Trollope et al., 1998; Brits et al., 2002). During the field work in the KNP, there was evidence of such physical damage to woody species due to elephant herbivory.

Careful selection of image dates is an important component of the protocol for detecting and monitoring change in woody vegetation cover on African savanna rangelands. As demonstrated in this paper, using imagery that was acquired during a season when the herbaceous vegetation is in senescence but the woody vegetation is in leaf is critical. Season partly accounts for the differences in amount of woody cover that was mapped for the 2001 and 2012 images in this study (Figures 3, 4; Table 3). On the September 2001 image, the woody vegetation that was detected was mainly that in river valleys whereas way from the river valleys the woody canopies were still in early spring leaf.

Using imagery from various sensors a number of studies have shown that spatial resolution is a determinant factor in the successful use of remote sensing to monitor bush encroachment (e.g. Hudak \& Wessman, 1998; 2001; McGlynn \& Okin, 2006; Pringle et al., 2009; Oldeland et al., 2010). High spatial resolution is vital in detecting the encroachment because of the small sizes of encroaching woody shrub canopies in savannas (e.g. see Figure 2 ), which requires a sensor that will detect the canopies. Given the high spatial resolution of the aerial photographs that were used (Table 1), more woody cover should have been detected on the aerial photographs than was detected (Table 3). Although more woody cover detail was detected on the higher resolution aerial photographs than on the SPOT images (Figures 3-5), the amount of woody cover that was detected on the aerial photographs was lessened by the failure of the sub-pixel classifier to detect portions of woody canopies that were under shadow as being part of the respective canopies. Without such an error, the results from this study indicate that historical aerial photographs are quite useful in detecting woody encroachers using sub-pixel classification because of their high spatial resolution (Figure 5). However, in order to integrate historical aerial photographs with the newer satellite imagery in an analysis of bush encroachment, the high spatial resolution of the aerial photographs needs to be degraded to the pixel size of the satellite imagery (e.g. Hudak \&Wessman, 1998).

The methods for quantifying woody vegetation cover in the field and on historical imagery shown by this research can contribute to the monitoring of bush encroachment on savanna rangelands and, ultimately, to remote sensing of environmental changes. Sub-pixel classification appears to be accurate in quantifying woody cover on high spatial resolution images of savannas. Not all woody savanna vegetation is a manifestation of bush encroachment, given the diverse drivers of change in savanna woody cover (Wigley et al., 2010). However, in places that are known to have been open savanna in the past, the occurrence of woody vegetation would be a manifestation of encroachment. The rate and 
extent of the encroachment can then be quantified using the procedures utilised in this research, which has shown the feasibility of linking multispectral satellite imagery and historical aerial photographs, including panchromatic photographs.

\section{Acknowledgements}

We acknowledge financial support from our respective institutions of affiliation (the University of Venda and North West University). The Scientific Services division of South African National Parks (SANParks) obtained the aerial photographs and availed them for this research, for which we are grateful. Further assistance from SANParks was through the provision of research site shapefiles, game guards for escort during field work, and accommodation at their research camps. Assistance with collection of field data by Tsundzukani Mzimba is gratefully acknowledged.

\section{References}

Bateson, CA, Asner, GP, Wessman, CA 2000, 'Endmember bundles: a new approach to incorporating endmember variability into spectral mixture analysis', IEEE Transactions on Geoscience and Remote Sensing, vol. 38, no. 2, pp. 1083-1094.

Brits, J, van Rooyen, MW \& van Rooyen, N 2002, 'Ecological impact of large herbivores on the woody vegetation at selected watering points on the eastern basaltic soils in the Kruger National Park', African Journal of Ecology, vol. 40, pp. 53-60.

Dennison, PE \& Roberts, DA 2003, 'Endmember selection for multiple endmember spectral mixture analysis using endmember average RMSE', Remote Sensing of Environment, vol. 87, pp. 123-135.

du Toit, JT \& Cumming, DHM 1999, 'Functional significance of ungulate diversity in African savannas and the ecological implications of the spread of pastoralism', Biodiversity and Conservation, vol. 8, pp. 1643-1661.

ERDAS Inc. 2010, ERDAS Systems Incorporated, Norcross, Georgia, USA.

Foody, GM 2002, 'Status of land cover classification accuracy assessment', Remote Sensing of Environment, vol. 80, no. 1, pp. 185-201.

Gertenbach, WPD 1983, 'Landscapes of the Kruger National Park', Koedoe, vol. 26, pp. 9-121.

Hudak, AT \& Wessman, CA 1998, 'Textural analysis of historical aerial photography to characterize woody plant encroachment in South African savanna', Remote Sensing of Environment, vol. 66, pp. 317-330.

Hudak, AT \& Wessman, CA 2001, 'Textural analysis of high resolution imagery to quantify bush encroachment in Madikwe Game Reserve, South Africa, 1955-1996', International Journal of Remote Sensing, vol. 22, no. 14, pp. 2731-2740.

Kraaij, T \& Ward, D 2006, 'Effects of rain, nitrogen, fire and grazing on tree recruitment and early survival in bush-encroached savanna, South Africa', Plant Ecology, vol. 186, pp. 235-246.

Laliberte AS, Rango A, Havstad KM, Paris JF, Beck RF, McNeely R \& Gonzalez AL 2004, 'Objectoriented image analysis for mapping shrub encroachment from 1937 to 2003 in southern New Mexico', Remote Sensing of Environment, vol. 93, pp. 198-210.

McGlynn, IO \& Okin, GS 2006, 'Characterization of shrub distribution using high spatial resolution remote sensing: Ecosystem implications for a former Chihuahuan Desert grassland', Remote Sensing of Environment, vol. 101, pp. 554-566. 
Meik, JM, Jeo, RM, Mendelson III, JR \& Jenks, KE 2002, 'Effects of bush encroachment on an assemblage of diurnal lizard species in central Namibia', Biological Conservation, vol. 106, pp. 29-36.

Moleele, NM, Ringrose, S, Matheson, W \& Vanderpost, C 2002, 'More woody plants? The status of bush encroachment in Botswana's grazing areas', Journal of Environmental Management, vol. 64, pp. 3-11.

O'Connor, TG \& Crow, VRT 1999, 'Rate and pattern of bush encroachment in Eastern Cape savanna and grassland', African Journal of Range \& Forage Science, vol. 16, no. 1, pp. 26-31.

Oldeland, J, Dorigo, W, Wesuls, D \& Jürgens, N 2010, 'Mapping bush encroaching species by seasonal differences in hyperspectral imagery', Remote Sensing, vol. 2, no. 6, pp. 1416-1438.

Pan, J \& Li, T 2013, 'Extracting desertification from Landsat TM imagery based on spectral mixture analysis and albedo-vegetation feature space, Natural Hazards, vol. 68, pp. 915-927.

Pringle, RM, Syfert, M, Webb, JK \& Shine, R 2009, 'Quantifying historical changes in habitat availability for endangered species: use of pixel- and object-based remote sensing', Journal of Applied Ecology, vol. 46, pp. 544-553.

Shackleton, CM 2000, 'Comparison of plant diversity in protected and communal lands in the Bushbuckridge lowveld savanna, South Africa', Biological Conservation, vol. 94, pp. 273-285.

Smit, IPJ, Riddell ,ES, Cullum,C \& Petersen, R 2013, 'Kruger National Park research supersites: Establishing long-term research sites for cross-disciplinary, multiscaled learning', Koedoe, vol. 55, no. 1, Art. \#1107, 7 pages, viewed 11 November 2013, <http://dx.doi.org/10.4102/koedoe.v55i1.1107>.

Trollope, WSW, Trollope, LA, Biggs, HC, Pienaar, D \& Potgieter, ALF 1998, 'Long-term changes in the woody vegetation of the Kruger National Park, with special reference to the effects of elephants and fire', Koedoe, vol. 41, pp. 103-112.

van Wilgen, BW, Biggs, HC, O'Regan, SP \& Mare, N 2000, 'A fire history of the savanna ecosystems in the Kruger National Park, South Africa, between 1941 and 1996', South African Journal of Science, vol. 96, pp. 167-178.

Wigley, BJ, Bond, WJ \& Hoffman, M 2010, 'Thicket expansion in a South African savanna under divergent land use: local vs. global drivers?', Global Change Biology, vol. 16, no. 3, pp. 964-976.

Witkowski, ETF \& Garner, RD 2000, 'Spatial distribution of soil seed banks of three African savanna woody species at two contrasting sites', Plant Ecology, vol. 149, no. 1, pp. 91-106. 